Disponível em

http://www.anpad.org.br/rac

RAC, Rio de Janeiro, v. 18, n. 6, art. 2, pp. 772-794, Nov./Dez. 2014

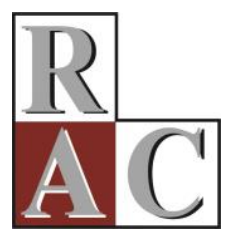

\title{
Oligopsônio dos Frigoríficos: Uma Análise Empírica de Poder de Mercado
}

\section{A Slaughterhouse Oligopsony: An Empirical Assessment of Market Power}

Rodrigo Menon Moita E-mail: rodrigomsm@insper.edu.br Insper Instituto de Ensino e Pesquisa Rua Quatá, 300, sala 418, Vila Olímpia, 04546-042, São Paulo, SP, Brasil.

Lucille Assad Golon E-mail: lucille.goloni@itau-unibanco.com.br Itaú-Unibanco Praça Alfredo Egydio de Souza Aranha, 100, Torre WMS, 04344-902, São Paulo, SP, Brasil. 


\title{
Resumo
}

Este estudo tem por objetivo analisar a cadeia de carne bovina de corte no Brasil e determinar, empiricamente, se há poder de mercado na relação comercial entre produtores rurais e frigoríficos. Com esse fim, procedeu-se em duas etapas. Primeiro, fez-se uma caracterização da estrutura da indústria. Concluiu-se que, de fato, a estrutura se aproxima de um oligopsônio, com potencial para exercício de poder de mercado. Na linha da Nova Organização Industrial Empírica (NOIE), o artigo desenvolve um novo método econométrico para auferir poder de mercado em indústrias oligopsônicas. Esse modelo procura superar uma limitação tradicional da literatura, na qual os resultados são sensíveis à hipótese feita sobre a tecnologia de produção. Usando a condição de maximização de lucro dos frigoríficos e dados mensais por um período de 14 anos para o estado de São Paulo, encontrou-se evidência de poder de mercado fraco no setor, o que permite descartar a hipótese de comportamento de cartel. Estimativas alternativas apenas reforçam a robustez desse resultado. Além disso, o poder de mercado não aumentou em anos recentes, quando a concentração no setor aumentou substancialmente.

Palavras-chave: frigorífico; estimação de poder de mercado; oligopsônio; antitruste.

\begin{abstract}
This paper analyzes the beef supply chain in Brazil with the purpose of identifying the existence of market power between farmers and slaughterhouses. The study is divided in two parts. First, we characterize the beef sector in Brazil, and conclude that the industry structure is close to a oligopsony. Following the tradition of the New Empirical Industrial Organization (NEIO), we then proceed to apply an econometric test to detect market power. This new method tries to overcome the usual limitations in which the results obtained are sensitive to assumptions about production technology. Using profit maximization conditions for slaughterhouses, and a time series of monthly data over a period of 14 years from the state of Sao Paulo, we found evidence of weak to moderate market power in the relationship between slaughterhouses and producers. Robustness checks through alternative models only confirmed these results. Also, we did not find evidence that market power has increased any in recent years, during which the industry concentration ratio has increased substantially.
\end{abstract}

Key words: slaughterhouse; market power estimation; oligopsony; antitrust. 


\section{Introdução}

A indústria frigorífica tem passado por mudanças significativas nos últimos anos. Além da tendência mundial de consolidação, o setor tem contado com apoio substancial do Banco Nacional do Desenvolvimento (BNDES) no processo de internacionalização de firmas brasileiras, via empréstimo e financiamento para operações de aquisições (ver, por exemplo, Governo federal dá prioridade a grandes frigoríficos, 2010). Críticos dessa política a acusam de incentivar a concentração setorial dentro do país. O fato é que o setor brasileiro de frigoríficos tem apresentado uma rápida concentração de sua estrutura produtiva. Neves (2000) calculou que os quatro maiores frigoríficos do Brasil na época (Bertin, Independência, Friboi e Minerva) detinham 54\% do mercado. Concentração essa que aumentou nos últimos anos, resultado principalmente das fusões e aquisições que ocorrem no setor.

De um modo geral, o benefício do aumento da concentração de uma indústria se dá principalmente via ganhos de escala de produção. Esse é o argumento que embasa tanto a defesa de operações de fusões horizontais entre empresas de uma mesma indústria frente ao órgão antitruste quanto políticas industriais de ganho de competitividade via aumento da concentração, cujo lado negativo é o aumento da possibilidade de exercício de poder de mercado pelas firmas. Diversos modelos de competição da literatura de organização industrial preveem uma relação inversa entre poder de mercado e número de firmas na indústria.

Concomitante com o aumento da concentração no setor - referendada pelo Conselho Administrativo de Defesa Econômica (CADE), algumas ações judiciais foram abertas contra os frigoríficos remanescentes com a alegação de coordenação de preços e práticas anticompetitivas. Em 2005, José Batista Júnior, na época presidente do frigorífico Friboi, foi envolvido em gravações que sinalizavam eventual esquema de cartel: os frigoríficos acordaram uma tabela de desconto para os pecuaristas (CADE, 2005). A denúncia partiu da Confederação Nacional de Abastecimento (CNA) e o assunto foi parar no Conselho Administrativo de Defesa Econômica (CADE) para investigação. Em 2007, o mesmo CADE (2005) condenou os frigoríficos Minerva, Bertin, Mataboi e Franco Fabril por conluio de preços, baseado na existência de uma tabela de desconto idêntica para todos esses frigoríficos; a multa foi de 5\% sobre o faturamento do ano de 2004. O frigorífico Friboi pagou R $\$ 13,7$ milhões e comprometeu-se a adotar práticas contra a colusão de preços, evitando, assim, a multa dos $5 \%$.

É nesse cenário de questionamento da política do BNDES, consolidação do setor e desconfiança em relação à conduta dos frigoríficos que este artigo procura mostrar empiricamente se há de fato exercício de poder de mercado na indústria de carne bovina no Brasil, e se o aumento recente da concentração alterou o padrão de concorrência do setor.

Este estudo tem dois objetivos distintos, porém complementares. O primeiro, e principal, é analisar a cadeia de carne bovina de corte no Brasil e determinar, empiricamente, se há poder de mercado na relação comercial entre produtores rurais e frigoríficos. Há tempos diz-se que a indústria frigorífica exerce poder de mercado sobre os produtores de gado de corte. No entanto poucos trabalhos no Brasil procuraram analisar essa questão de modo rigoroso. Este trabalho busca se juntar a esse restrito grupo para tentar analisar essa relação de maneira científica.

O segundo objetivo é propor um método de estimação na linha da Nova Organização Industrial Empírica que seja robusto a diferentes formas funcionais adotadas e leve em conta as especificidades tecnológicas dessa indústria. A literatura que trata do assunto é relativamente extensa, mas largamente inconclusiva sobre a existência ou não de poder de mercado. Parte da razão para isso é a dependência dos resultados em relação a hipóteses sobre a forma funcional dos modelos. De maneira sucinta, o método aqui desenvolvido assume que a produtividade marginal é constante, limitada pelo processo produtivo - não pode ser maior do que um, pois um quilograma de boi gordo não pode render mais do que um quilograma de carne bovina -, e deve ser estimada através da equação de maximização de lucro da firma. Vale destacar que essa metodologia pode ser empregada em diferentes contextos, como será discutido mais adiante. 
Para atingir os objetivos propostos, dividiu-se o estudo em duas partes. Primeiro, foram analisadas a evolução e a estrutura dos dois elos da cadeia de produção de carne bovina que interessa ao estudo a relação entre produtor rural e frigorífico. Em seguida, estimou-se econometricamente a existência de poder de mercado.

A conclusão tirada da primeira parte é direta: os produtores rurais são muitos e distribuídos pelos principais estados produtores, enquanto os frigoríficos são grandes e poucos. Isso sustenta a hipótese de que a indústria tem a estrutura de um oligopsônio e que, portanto, tem potencial para exercer poder de mercado sobre os produtores rurais.

Usando dados mensais por um período de 14 anos, estimou-se um modelo de conduta oligopsônica que busca estimar o parâmetro que descreve as relações desse mercado. Os resultados mostram evidência de poder de mercado entre fraco e moderado, compatível com um oligopsônio, mas não com um cartel, apesar da estrutura com potencial para exercício de poder de mercado.

Este trabalho procede da seguinte maneira. Primeiramente, descreve a cadeia de produção da carne bovina e a evolução do mercado de carne nacional ao longo dos anos, além de relatar a estrutura da indústria de carne e o funcionamento de suas relações comerciais. Em seguida, faz uma revisão da literatura sobre o assunto, apresenta o modelo de oligopsônio utilizado para estimar o poder de mercado do setor e discute as várias hipóteses necessárias para a obtenção das estimativas procuradas. A parte empírica inicia-se com a apresentação da base de dados utilizada, para posteriormente mostrar os resultados obtidos. No fim, há uma conclusão com os principais pontos do artigo.

\section{Produtores Rurais e Frigoríficos}

O mercado de carne bovina no Brasil passou por algumas importantes mudanças ao longo de três décadas. Em 1980, o Brasil já detinha o quarto maior rebanho bovino do mundo, com aproximadamente 90 milhões de reses, sendo superado apenas pela antiga URSS, Índia e Estados Unidos (YardleyPodolsky, 1981). Em 1990, estava em segundo lugar, com cerca de 150 milhões de reses e, em 2009, continuava listado como o segundo maior rebanho, com aproximadamente 200 milhões de reses, perdendo somente para a Índia (Pita, 2013) $)^{(1)}$.

As significativas mudanças tecnológicas ocorridas nesse setor merecem menção. Enquanto os anos 1980 foram marcados por doenças e oferta inconstante de carne (Yardley-Podolsky, 1981), as evoluções tecnológicas, como a inseminação artificial, transferência de embriões, a redução do tempo de abate, além do aparecimento de novilho superprecoce com tempo de abate de 13 meses (Novilho Superprecoce, 2009), levaram o Brasil a consolidar-se como peça importante no mercado de mundial de carne.

Não só os fatores relativos à criação de bovinos se alteraram, os frigoríficos também sofreram importantes mudanças, principalmente na forma como eram estruturados. De pequenos e pulverizados (210 estabelecimentos legalizados no final dos anos 1970, com abate de 50.000 cabeças/ano - Instituto Brasileiro de Geografia e Estatística [IBGE], n.d.) para grandes e estrategicamente localizados nas regiões de maior produção e consumo de carne, ou seja, nos estados de São Paulo, Mato Grosso, Mato Grosso do Sul, Minas Gerais e Goiás: 80 plantas em 2009, com abate médio de 185.000 cabeças/ano (Associação as Indústrias Brasileiras Exportadores de Carne [ABIEC], 2009; IBGE, 2008).

Em 2007, o frigorífico Friboi adquiriu a Swift, empresa norte-americana, e tornou-se o JBS-Friboi, assim, passando a ser o maior frigorífico do mundo (Dinheiro Rural, 2009). Os frigoríficos Minerva e Marfrig também iniciaram, no mesmo período, um rápido processo de internacionalização. Também em 2007, Friboi teve suas ações negociadas na Bolsa de Valores (BOVESPA), sendo a primeira empresa brasileira de processamento de carne a abrir o capital. No mesmo ano, o frigorífico Marfrig também anunciou a abertura de seu capital, seguido do Minerva. 
Inúmeras operações de fusões e aquisições vêm contribuindo para a consolidação do setor no Brasil. As mais relevantes, pelo seu grande porte, foram a aquisição do frigorífico Bertin pelo grupo JBS-Friboi, em 2009, a aquisição de plantas dos frigoríficos Margen e Mercosul pelo Marfrig, além do grupo SEARA de alimentos, e o encerramento das operações do frigorífico Independência com a aquisição, em 2013, dos seus ativos pela JBS-Friboi (Macedo \& Lima, 2011).

As operações de fusões e aquisições têm sido referendadas pelo CADE, porém algumas vezes com restrições, como é o caso da aquisição das plantas do frigorífico Mercosul pelo Marfrig. Frequentemente, o problema principal consiste em um excesso de concentração regional (CADE, n.d.).

De acordo com Caleman e Cunha (2011), em 2007, os cinco maiores frigoríficos detinham a seguinte participação de mercado: JBS-Friboi, 15,8\%; Bertin, 13,7\%; Minerva, 8,1\%; Marfrig, 6,9\%; e Independência, 5,3\%. Considerando somente as operações de aquisição do Bertin e dos ativos do Independência - e supondo que a aquisição dos ativos equivale à incorporação de seu market share, eleva a participação de mercado do JBS-Friboi para 34,8\%. Um aumento expressivo tanto na concentração do setor quanto na assimetria de tamanho entre as principais firmas. Vale destacar que há um grande número de firmas de pequeno porte, muitas delas operando clandestinamente.

\section{Estrutura da indústria}

Como já colocado, a estrutura da indústria de carnes no Brasil passou por uma notável alteração no período de 30 anos. Tanto os produtores como os frigoríficos tornaram-se mais eficientes à medida que implementaram novas tecnologias para criação e abate de animais, melhorando, assim, a qualidade da carne e garantindo uma oferta mais constante ao consumidor final. Porém, ao contrário dos frigoríficos que reduziram a quantidade de plantas, os pecuaristas continuaram espalhados pelo país com uma produção pequena por produtor. Em termos econômicos, pode-se dizer que a indústria de carnes no Brasil se assemelha a de um oligopsônio: muitos ofertantes (pecuaristas) e poucos demandantes (frigoríficos).

Tabela 1

Quantidade Média de Bovinos por Produtores no Brasil (1980 - 2009)

\begin{tabular}{lcccc}
\cline { 2 - 5 } & $\mathbf{1 9 8 0}$ & $\mathbf{1 9 8 5}$ & $\mathbf{1 9 9 5 - 1 9 9 6}$ & $\mathbf{2 0 0 9}$ \\
\hline Produtores* & 3.390 .582 & 3.748 .024 & 3.604 .343 & - \\
Bovinos & 118.085 .608 & 128.041 .757 & 153.058 .275 & 205.686 .000 \\
Rebanho Médio/Produtor & 35 & 34 & 42 & - \\
\hline
\end{tabular}

Nota. Fonte: Instituto Brasileiro de Geografia e Estatística. (1997). Censo agropecuário 1995-1996. Rio de Janeiro: Autor. * Proprietários de terra.

Segundo o Censo Agropecuário realizado pelo IBGE com referência ao ano de 2006, em que foi medido o número médio de cabeças por produtor rural, 33,99\% dos pecuaristas têm até nove animais; $53,97 \%$ possuem de 10 a 99; 9,60\%, de 100 até 499; e 2,42\% possuem acima de 500 animais.

Observa-se na Tabela 2 que, historicamente, os maiores rebanhos se concentram nos mesmos estados, mantendo uma participação relativamente constante no quadro de maiores produtores. Destacase apenas o estado do Mato Grosso que, em 1980, detinha 4,44\% de participação e, em 2009, 12,67\% (tornando-se o maior estado em criação de bovinos). São Paulo, apesar de não fazer parte dos estados com os maiores rebanhos, deve ser levado em consideração já que é responsável por 13,3\% do total de bovinos abatidos no Brasil (IBGE, Estatística da Produção Pecuária, 2009) e, segundo estudo de Urso (2007), é um centro formador de preços no país, além de ser o maior estado em exportação de carne. 
Tabela 2

Estados Brasileiros com Maiores Rebanhos Bovinos em 2009 e Evolução do Rebanho

\begin{tabular}{lcccccccc}
\cline { 2 - 9 } & $\mathbf{1 9 8 0}$ & Part (\%) & $\mathbf{1 9 8 5}$ & Part (\%) & $\mathbf{1 9 9 5 - 1 9 9 6}$ & Part (\%) & $\mathbf{2 0 0 9}$ & Part (\%) \\
\hline Mato Grosso & 5.243 .044 & $4,44 \%$ & 6.545 .956 & $5,11 \%$ & 14.438 .135 & $9,43 \%$ & 26.064 .000 & $12,67 \%$ \\
Minas Gerais & 19.560 .399 & $16,56 \%$ & 19.983 .506 & $15,61 \%$ & 20.044 .616 & $13,10 \%$ & 22.500 .000 & $10,94 \%$ \\
$\begin{array}{l}\text { Mato Grosso } \\
\text { do Sul }\end{array}$ & 16.862 .907 & $14,28 \%$ & 15.017 .906 & $11,73 \%$ & 19.754 .356 & $12,91 \%$ & 22.000 .000 & $10,70 \%$ \\
Goiás & 16.089 .510 & $13,63 \%$ & 14.476 .565 & $11,31 \%$ & 16.488 .390 & $10,77 \%$ & 20.200 .000 & $9,82 \%$ \\
\hline
\end{tabular}

Nota. Para 2009, estimativa nos sites dos governos dos estados. Fonte: Instituto Brasileiro de Geografia e Estatística. (1997). Censo agropecuário 1995-1996. Rio de Janeiro: Autor.

É importante ressaltar que os estados com os maiores rebanhos também são os que possuem a maior quantidade de plantas frigoríficas. Isso pode ser explicado pela dificuldade e custo da locomoção do boi vivo das fazendas para os matadouros. O boi, quando viaja por longas distâncias, pode sofrer de estresse, perda de peso e, principalmente, machucar-se durante o trajeto. Características ruins tanto para o produtor, que ganhará menos pelo seu produto já que ele pesará menos, quanto para o frigorífico, que produzirá uma carne de qualidade inferior.

\section{Relações comerciais entre produtores e frigoríficos}

O transporte dos bovinos das fazendas até os frigoríficos se dá quase exclusivamente por meio de rodovias. Como o transporte de bovinos é de difícil execução, pois o animal deve ficar o menor tempo possível exposto ao sol, sem água e sem alimento, e o meio rodoviário é um dos mais caros existentes, o frete do boi gordo hoje tem um custo elevado, por volta de $\mathrm{R} \$ 2,70 / \mathrm{km}$, em um caminhão com capacidade de transportar 45 animais. Esse valor é arcado pelos frigoríficos, que geralmente possuem uma frota própria e embutem no preço pago aos produtores o custo por esse transporte. Conforme Bailey, Brorsen e Thomsen (1995), o preço pago pela carne aos produtores nos Estados Unidos é uma função decrescente da distância que o gado terá de percorrer, já que são os frigoríficos que pagam o transporte.

Segundo Urso (2007) e Yatabe (2004), o peso da carne de um boi abatido representa em média $52 \%$ do peso total do animal. O preço pago para o pecuarista é apenas sobre a carne do animal. Por exemplo: paga-se o preço de 52 duas arrobas por um animal de 100 arrobas. Essa informação será relevante na parte empírica deste trabalho.

\section{Literatura}

A Nova Organização Industrial Empírica (NOIE) surge como uma resposta às críticas à literatura conhecida como Estrutura-Conduta-Desempenho (ECD). A abordagem principal da ECD é estimar a relação entre lucratividade e concentração da indústria. Essa literatura assume que poder de mercado, ou margem de lucro, é observado e procura identificar variáveis que expliquem o poder de mercado. Um exemplo típico dessa literatura é regredir lucro contra o índice de concentração de HerfindhalHirschman para uma cross section de indústrias. Schmalensee (1989) analisa o desenvolvimento dessa literatura durante os anos de 1980.

Esses modelos foram duramente criticados com base no fato de que estrutura e desempenho são endógenos ao equilíbrio da indústria. Desempenho teria um efeito retroativo sobre a estrutura: firmas com baixa lucratividade podem fechar ou ser adquiridas por outras firmas, resultando em um processo de concentração da indústria. Logo, não haveria uma relação causal entre estrutura e desempenho. A endogeneidade da variável estrutura tornaria os resultados econométricos viesados. 
A NOIE, por outro lado, assume que a margem não é observada, e o objetivo principal é justamente estimar o grau de poder de mercado na indústria. Poder de mercado é tratado como um parâmetro desconhecido. Bresnahan (1989) e Perloff, Karp e Golan (2007) discutem e comparam a NOIE com a ECD.

Três abordagens principais são usadas para estimar poder de mercado. A primeira, desenvolvida por Appelbaum (1982), estima o parâmetro de conduta - que mede o poder de mercado - através da estimação de uma função custo e da condição de maximização da firma. A segunda, iniciada por Bresnahan (1982) e Lau (1982), determina um sistema de oferta e demanda e usa a variação de preço de um bem substituto para identificar o grau de poder de mercado na indústria. Finalmente, Baker e Bresnahan (1988) avaliam a demanda residual da firma, onde o poder de mercado é dado pelo inverso da elasticidade-preço da demanda residual da firma de interesse.

Todos esses artigos objetivam estimar poder de mercado na venda de um produto. O de Schroeter (1988), pioneiro, adapta o método de Appelbaum (1982) para a estimação de poder de mercado na compra de um produto: poder de oligopsônio ao invés de oligopólio. Ele encontra evidência de baixo poder de mercado na compra de bovinos pela indústria frigorífica.

A partir desse artigo se desenvolve a literatura de estimação de poder de oligopsônio, com um grande número de aplicações em mercados de insumos agropecuários. As três metodologias básicas também são usadas na estimação de poder de mercado na compra. Durham e Sexton (1992) e Andersen, Asche e Roll (2008), entre outros, usam o método da oferta residual (análogo à demanda residual de Baker \& Bresnahan, 1988) para estimar poder de oligopsônio nos mercados de tomate e de bacalhau, respectivamente.

Analisando o setor de carne bovina, Schroeter et al. (2000) usam a metodologia criada por Bresnahan (1982) e Lau (1982) para analisar poder de mercado no mercado atacadista de carne nos EUA. Sua abordagem é analisar poder de mercado nos dois lados do mercado, compradores (supermercados) e vendedores (supermercados), simultaneamente. Eles concluem pela rejeição da hipótese de competição perfeita nos dois lados do mercado.

Dentro dessas três abordagens da NEIO, além do artigo pioneiro de Schroeter (1988), um grande número de artigos procuram analisar competição e poder de mercado no mercado de gado e carne bovina. Essa ênfase provavelmente decorre do aumento da concentração nesse setor nos Estados Unidos, de 25\%, em 1977, para 80\%, em 2007 (Crespi, Xia, \& Jones, 2010).

Stiegert Azzam e Brorsen (1993), em seu estudo, analisam o efeito da disponibilidade de oferta do boi e a concentração do mercado nos preços praticados pelos frigoríficos. E concluem que a redução ou o aumento da concentração provavelmente não leva a uma mudança nos preços praticados, mas o que faz os preços se alterarem são as variações da oferta. Koontz, Garcia e Hudson (1993), por sua vez, observam a conduta dos frigoríficos na precificação da carne de boi nos Estados Unidos. O resultado do estudo mostra evidência de conduta cooperativa em todos os mercados analisados, porém é uma tendência decrescente.

Já Bailey et al. (1995) examinam o mercado relevante do produto de interesse por meio da Teoria do Mercado Espacial para determinar o impacto da concentração nos preços dos bois. O resultado da estimação sugere que os frigoríficos se comportam como oligopsonistas quando se localizam em um mesmo mercado relevante e oferecem um preço mais elevado pelo gado em função da sobreposição de dois ou mais mercados. Paul (2001) relata sobre as economias de custos causadas pela concentração de mercado e seus impactos na existência de poder de mercado. Os resultados obtidos indicaram que as variáveis que determinam poder de mercado são significantes, embora sua exploração seja pequena.

Ji e Chung (2010) estimam poder de mercado no setor frigorífico dos Estados Unidos. Apesar do método e do interessante resultado indicando a existência de poder de mercado, o modelo depende fortemente da forma funcional adotada para a função custo - uma função do tipo Leontief. 
Lopez, Azzam e Lirón-España (2002) também examinam o mercado de carne norte-americano, entre outras indústrias, mas sua análise é sobre poder de mercado versus eficiência em indústrias concentradas. Eles concluem que poder de oligopólio domina ganhos de escala nesse mercado.

Outra vertente dessa literatura, relevante para o mercado de bovinos, é a que analisa o efeito de oferta cativa sobre poder de mercado. Vários artigos - tais como Ward, Koontz e Schroeder (1998), Zhang e Sexton (2000), Schroeter e Azzam (2004), entre outros - apresentam uma relação negativa entre oferta cativa e poder de mercado: quanto maior o percentual de oferta cativa, menor o preço pago aos produtores, sendo uma evidencia de poder de mercado dos compradores.

Zheng e Vukina (2009) avaliam, em sua pesquisa, o efeito de oferta cativa em modelo de NEIO. Eles analisam o mercado de suínos vivos nos Estados Unidos. Os autores concluem pela existência de poder de mercado na compra de suínos, mas afirmam que a existência de oferta cativa não é o fator determinante do poder de mercado.

Crespi, Xia e Jones (2010) consideram o efeito do ciclo da oferta de gado no poder de mercado dos frigoríficos. E concluem que períodos com grandes rebanhos de gado de corte magnificam o poder de mercado dos compradores. Cai, Stiegert e Koontz (2011) estimam um modelo econométrico que permite mudanças no estado da competição do mercado. Especificamente, o modelo permite identificar períodos de cooperação entre os frigoríficos e períodos de competição mais intensa. Esse resultado é consistente com teorias de coalisão, em que períodos de cooperação e de punição se alternam. Interessantemente, o artigo estima poder de oligopsônio substancial nos períodos de cooperação, mas não nos períodos não cooperativos. Esse resultado ajuda a explicar o baixo grau de poder de mercado médio estimado em muitos artigos.

Pode-se perceber que os estudos realizados nos Estados Unidos referentes a poder de mercado e concentração não chegam a um consenso sobre a existência de um poder de mercado ou se há evidências claras de que o aumento da concentração dos frigoríficos leve a práticas anticompetitivas. A maior parte dos estudos citados - Schroeter (1988), Crespi, Gao e Peterson (2005), entre outros - procura estimar a produtividade marginal do boi gordo na produção de carne, tanto via estimação de uma função de produção quanto estimação da produtividade marginal na condição de maximização de lucro. Apesar de conceitualmente correta, essa abordagem esbarra no problema de que os resultados obtidos não são robustos às diferentes especificações da função de produção, o que os torna fracos e de pouco uso prático.

Esse artigo propõe um método robusto à forma funcional adotada para função de produção ou custo, hipótese feita por praticamente toda a literatura. O método de estimação se assemelha ao método de Bresnahan (1982) e Lau (1982), porém adaptado para mercados de insumos e estimação de poder de oligopsônio. No cerne desse método está a hipótese de que a produtividade marginal é constante e com limites claros dados pelo processo produtivo: um quilograma de boi gordo não pode gerar mais do que um quilograma de carne bovina. A produtividade marginal é estimada diretamente da condição de maximização de lucro da firma.

Existem poucos estudos dessa natureza no Brasil. O estudo desenvolvido por Urso (2007) analisa o efeito das assimetrias de informações nas relações comerciais entre pecuaristas e frigoríficos e frigoríficos e supermercados. Os frigoríficos exercem poder de mercado na compra de bois junto aos pecuaristas, segundo os resultados desse estudo, mas estes variam de acordo com as localidades analisadas; o mesmo vale para áreas formadoras de preço. Caleman e Cunha (2012) avaliam o desempenho da cadeia de carne bovina usando a teoria Estrutura-Conduta-Desempenho e de mercados contestáveis. Eles concluem que há a possibilidade de exercício de poder de mercado pelas empresas líderes.

Pitelli e Mendonça (2008) usam a metodologia DEA (Análise Envoltória de Dados) para analisar o efeito de fusões entre frigoríficos na sua eficiência. Os resultados indicam que a fusão entre firmas eficientes e firmas não eficientes elevam a eficiência e o bem-estar dos consumidores. Esse é um resultado importante para justificar a recente onda de fusões no setor. 
Como no Brasil existem poucos estudos empíricos sobre poder de mercado na cadeia de carne bovina de corte, este artigo pretende contribuir para o enriquecimento da literatura existente, adotando um método distinto de estimação.

\section{Metodologia}

Utilizou-se a abordagem da Nova Organização Industrial Empírica para analisar o mercado de bovinos entre frigoríficos e pecuaristas. Como já mencionado, o problema foi abordado em duas etapas. A primeira consistiu na descrição da evolução recente e da estrutura da indústria, como já mostrado no texto. O objetivo dessa parte foi compreender a organização desse mercado, entender o potencial dos frigoríficos para o exercício de poder de mercado e embasar as duas hipóteses necessárias, descritas a seguir, para levar a cabo a análise econométrica do problema.

A segunda etapa foi a análise econométrica de poder de mercado, seguindo a tradição da NOIE de derivar o modelo econométrico a partir de um modelo microeconômico de comportamento dos agentes. A derivação do modelo de comportamento dos frigoríficos assume duas premissas centrais: (a) que os pecuaristas não detêm poder de mercado, comportando-se de maneira competitiva, e (b) que os frigoríficos não possuem poder de mercado na venda de carne.

Como visto anteriormente, os pecuaristas são, em geral, pequenos em relação ao tamanho dos frigoríficos, o que justifica a hipótese (a). Além disso, o mercado atacadista de carne é composto por grandes compradores - redes de supermercados, grandes intermediadores e exportadores - o que torna a relação dos frigoríficos e os compradores equilibrada, com menos margem para exercício de poder de mercado. Essas duas hipóteses foram assumidas como verdadeiras e, portanto, não foram testadas neste trabalho.

\section{Um modelo de oligopsônio}

Ao contrário do que se faz no caso do oligopólio, em um oligopsônio, tenta-se medir o grau de poder de mercado dos demandantes (frigoríficos) com relação aos ofertantes (pecuaristas).

Nessa perspectiva, assumiu-se que o mercado atacadista de carne é competitivo, hipótese que se baseia em dois fatos observados. Primeiro, os grandes compradores de carne no atacado são empresas de médio e grande porte, redes de supermercados, intermediadores etc. e, portanto, configuram uma estrutura muito mais concentrada do que a dos produtores rurais. Segundo, o produto comercializado no mercado de carne, carne congelada, é facilmente transportado por grandes distâncias, havendo inclusive competição de carne importada de outros países. Esse baixo custo de transporte, somado ao fato de que carne congelada tem pouca diferenciação, torna esse um mercado propício à competição via preço e, portanto, provavelmente competitivo. Isso posto, volta-se agora para o problema da compra de boi de um frigorífico.

Frigoríficos escolhem a quantidade de bovinos que desejam abater para maximizar a seguinte função lucro:

$$
\pi=p f(B, N)-w_{B} B-w_{N} N
$$

Onde $p$ é o preço da carne e $w_{B}$ é o preço do boi gordo, $w_{N}$ é um vetor de preços dos insumos não agrícolas, $B$ é quantidade abatida de boi gordo e $N$ é o vetor das quantidades dos insumos não agrícolas utilizados pelo frigorífico. $Q=f(B, N)$ é a função de produção dos frigoríficos.

A condição de primeira ordem da equação (1) pode ser escrita como: 


$$
p_{c} f_{B}-w_{B}-\frac{\partial w_{B}}{\partial B} B=0
$$

Que rearranjada pode ser reescrita como:

$$
\frac{p_{C} f_{B} \quad w_{B}}{w_{B}}=\frac{w_{B}}{B} \frac{B}{w_{B}}=\frac{1}{B}
$$

Onde $\varepsilon_{B}$ é a elasticidade-preço da oferta de boi dos pecuaristas.

A equação (2) denota que se os frigoríficos se organizam como um cartel perfeito, então, eles comprarão boi dos pecuaristas até o ponto que o mark-up da indústria, termo do lado esquerdo da equação (2), iguala-se ao inverso da elasticidade da oferta de boi gordo. Esse resultado é análogo ao resultado de um oligopólio cartelizado, onde o índice de Lerner (mark-up) se iguala ao inverso da elasticidade-preço da demanda. As principais diferenças são que, neste caso, o mark-up é medido através da diferença entre o produto marginal em reais de uma unidade de boi e o preço da unidade de boi (quilograma no caso do Brasil), e este se iguala ao inverso da elasticidade-preço da oferta de boi gordo.

Porém, caso o mercado de boi gordo seja competitivo, o termo $\frac{\partial w_{B}}{\partial B}$ é igual a zero, e a equação (2) implica em $p f_{B}=w_{B}$. Essas duas situações extremas, cartel e competição perfeita, mostram como identificar a conduta competitiva do setor. Cria-se, então, o parâmetro $\theta$, que é obtido da seguinte relação:

$$
\frac{p_{C} f_{B} \quad W_{B}}{W_{B}}=-\frac{}{B}
$$

O parâmetro $\theta$ faz com que a equação (3) englobe uma série de estruturas diferentes de mercado. Se $\theta=0$, o mercado se encontra em concorrência perfeita e a receita marginal da compra dos bois será igual ao preço do boi gordo; se $\theta=1$ então o mercado se encontra cartelizado. Valores intermediários de $\theta$ implicam presença de uma estrutura de mercado oligopsônica.

Para se compreender os determinantes do $\theta$, reescreve-se a equação (3) da seguinte forma:

$$
\theta=\varepsilon_{B}\left(\frac{p_{c} f_{B}-w_{B}}{w_{B}}\right)
$$

Nota-se que o termo theta é função crescente de dois argumentos, o mark-up (1) e a elasticidade da oferta (2). Para compreender o significado da equação (5), imagine o caso de um monopólio cuja demanda é inelástica. Nessa situação, o monopolista tem, contudo, o mais constante - melhores condições de extrair ganhos de monopólio, uma vez que a demanda é inelástica, e os consumidores não reagirão fortemente a mudanças no preço. Ou seja, o ofertante conseguiria obter um elevado mark-up, dada a característica da demanda. Todavia, se, mesmo com essa condição favorável, o monopolista não conseguir fixar um mark-up significativo, provavelmente, o poder de mercado dele será baixo. Tal característica pode ser imediatamente extrapolada para o caso de um monopsônio.

\section{Estimadores}

O objetivo deste estudo foi estimar o poder de mercado dos frigoríficos. Para esse fim, usaram-se as equações (4) e (5). Portanto, dadas as séries de preços da carne $\left(p_{c t}\right)$ e de preços do boi gordo $\left(w_{B t}\right)$, para obter o parâmetro theta, fez-se necessário conhecer a produtividade do insumo boi gordo $\left(f_{B t}\right)$ e a elasticidade-preço da oferta $\left(\varepsilon_{B t}\right)$. Esses dois parâmetros precisaram ser estimados. Começando, para tanto, pela elasticidade da oferta. 


\section{Elasticidade da oferta}

Para obter a elasticidade da oferta, é necessário estimar a função oferta de boi gordo. O modelo estimado foi o seguinte:

$$
B=\beta_{0}+\beta_{1} w_{B}+\beta_{2} B_{t-1}+\beta_{3} R e b+\beta_{4} C n+\beta_{5} P b z+\beta_{6} t+\sum_{m=2}^{12} \delta_{m}+e
$$

Onde $B$ é quantidade de bois ofertados (abatidos) e $B_{t-l}$ é a oferta defasada em um período; $w_{B}$ é o preço que o boi é ofertado aos frigoríficos; Reb é o tamanho do estoque de bovinos no período; $C n$ é o preço da cana-de-açúcar, uma cultura que compete com a produção de bovinos no estado de São Paulo; $P b z$ é o preço do bezerro, um insumo básico na produção de bovinos; $t$ é uma tendência temporal; e $\delta_{m}$ são dummies mensais ${ }^{(2)}$.

A elasticidade da oferta então é dada por:

$$
\varepsilon_{B}=\beta_{1} \frac{w_{B}}{B}
$$

As regressões foram todas estimadas via $2 S L S$ (mínimos quadrados de dois estágios) para se tratar do problema da endogeneidade da variável preço na equação da oferta.

\section{Produtividade marginal}

O segundo parâmetro que precisa ser estimado é a produtividade marginal de um quilograma de boi com respeito à produção de carne: o termo $f_{B}$ nas equações (3) e (4).

A abordagem tradicionalmente usada na literatura - Schroeter (1988), Crespi et al. (2005), Ji e Chung (2010), entre outros - consiste em estimar uma função de produção e, então, calcular o efeito marginal, ou especificar uma forma funcional para a função de produção, derivar o efeito marginal e, usando essa forma derivada, estimá-la diretamente como parte da condição de maximização de lucro, dada pela equação (3). Em ambas as abordagens, é necessário especificar uma forma funcional, em geral complexa, e as variáveis que afetam a produtividade marginal. De um modo geral, os resultados são fortemente dependentes das especificações utilizadas, o que os torna fracos e de pouco uso prático em política antitruste, por exemplo.

Neste trabalho, foram aplicados dois métodos distintos àqueles usados pela literatura descrita acima. O uso de dois métodos distintos permite a comparação dos resultados. Assim, começa-se pelo uso da condição de primeira ordem.

\section{Condição de primeira ordem}

Primeiro, usa-se a condição de primeira ordem da maximização de lucro do frigorífico para estimar a produtividade marginal. A condição de primeira ordem resulta em uma relação direta entre preço da carne, preço do boi e produtividade marginal. Assume-se ainda que há um ruído no preço da carne cobrado pelos frigoríficos - cada frigorífico consegue preços diferentes pela carne que produz observado pela firma, mas não pelo econometrista. Isso faz com que a condição de primeira ordem observada, ou a equação (4) acima, assuma a seguinte forma:

$$
\left(p_{c t}+\delta_{t}\right) f_{B}-w_{B}-\theta \frac{\partial w_{B}}{\partial B} B=0
$$

Onde $\delta_{t}$ é o ruído. Além disso, assume-se que $\delta_{t}$ se decompõe em duas partes aditivas: $\delta_{t}=$ $\varphi\left(Z_{t}\right)+v_{t}$. Parte do ruído pode ser explicada por variáveis que descrevem as condições do mercado, $\varphi\left(Z_{t}\right)$, onde $Z_{t}$ é o vetor de variáveis que afetam o equilíbrio do mercado, $\varphi($.$) é uma função, e parte é$ um termo aleatório $v_{t}$, com distribuição $N\left(0, \sigma^{2}\right)$. Ao isolar-se o preço da carne na equação acima, obtém-se: 


$$
p_{c t}=\frac{w_{B t}}{f_{B}}+\frac{\theta}{f_{B}} \frac{w_{B t}}{\varepsilon_{B t}}-\varphi\left(Z_{t}\right)-v_{t}
$$

Onde $\varepsilon_{B t}$ é a elasticidade preço da oferta de bovinos no período $t$. Substituindo as variáveis desconhecidas, $\theta$ e $f_{B}$, por parâmetros a serem estimados, e assumindo que a função $\varphi$ é linear, obtémse o seguinte modelo econométrico:

$$
p_{c t}=\alpha_{1} w_{B t}+\alpha_{2} \frac{w_{B t}}{\varepsilon_{B t}}+Z_{t} \gamma+v_{t}
$$

Os parâmetros estimados que são úteis são $\alpha_{1}$ e $\alpha_{2}$. Com eles, consegue-se recuperar os parâmetros de interesse $f_{B}=1 / \alpha_{1}$ e $\theta=\alpha_{2} / \alpha_{1}$. Implicitamente, assume-se que a produtividade marginal é constante, um parâmetro fixo. Por outro lado, a elasticidade varia conforme mudam as condições de mercado.

\section{Informação a priori}

O segundo método usa informação a priori sobre a produtividade marginal para estimar o poder de mercado. Essas informações consistem em restrições impostas por características específicas da indústria frigorífica para determinar, ao invés de estimar, a produtividade marginal do boi gordo na produção de carne.

O ponto de partida é reconhecer que a produção de carne bovina é um processo de transformação de um insumo em um produto - boi gordo em carne bovina - em uma produtividade limitada: uma arroba de boi gordo não pode gerar mais que uma arroba de carne bovina. Outra maneira de entender esse processo produtivo é considerá-lo uma desmontagem do boi em carne para consumo. Essa característica existe em inúmeros processos produtivos: transformação de minério de ferro em aço, canade-açúcar em álcool, laranja em suco de laranja, petróleo em gasolina, etc.

Os demais insumos de produção são o trabalho e os insumos que compõem a infraestrutura da produção, tal como água e eletricidade, e devem interagir com a quantidade de boi gordo. Enquanto esses outros insumos determinam a quantidade produzida e custo de uma planta frigorífica, eles pouco ou nada alteram a produtividade marginal do boi gordo. Por consequência, assume-se que a produtividade marginal é fixa.

Conversas com diversas pessoas ligadas à indústria frigorífica ou pecuaristas informaram que um boi gordo produz a metade do seu peso em carne. Ademais, limitações da produção devido à escassez de insumos como água e eletricidade são raras no estado de São Paulo. Isso permite inferir que, não havendo restrição quanto ao uso dos demais insumos, a produtividade marginal do boi gordo é igual a 0,5. No entanto os pecuaristas são remunerados somente por metade do peso do animal, justamente por esta ser a fração comercializável do boi: um animal de 500 quilogramas vale o preço do quilo do boi gordo vezes 250 . Isso equivale a ajustar o preço dos insumos de tal forma que a produtividade marginal seja igual a um; um quilograma de boi gordo produz um quilograma de carne. Portanto, usou-se $f_{B}=1$. Essa hipótese foi confrontada com o resultado obtido com a estimação da condição de primeira ordem.

Usando a equação (5) e dadas as hipóteses, um estimador não viesado e consistente para o parâmetro de conduta pode ser obtido da média dos thetas dos períodos:

$$
\hat{\theta}=\frac{1}{T} \sum_{t=1}^{T}\left(\frac{p_{c t}-w_{B t}}{w_{B t}}\right) \varepsilon_{B t}
$$

Essa equação deve ser levada aos dados. 


\section{Descrição dos Dados}

Os dados se referem ao estado de São Paulo. Esse estado foi escolhido devido à sua importância na produção de carne no Brasil e por ser o único estado a disponibilizar publicamente os dados necessários para este estudo. O período analisado foi desde julho de 1994 até dezembro de 2008, em cotações mensais. Estatísticas descritivas das séries de dados estão disponíveis na Tabela 3.

Tabela 3

\section{Estatísticas Descritivas}

\begin{tabular}{lccccc}
\hline Variável & Observações & Média & Desvio Padrão & Mínimo & Máximo \\
\hline Número de abatidos (cabeças) & 186 & 163732 & 39612 & 83852 & 256391 \\
Rebanho efetivo (cabeças) & 186 & 37800000 & 886407 & 36600000 & 39400000 \\
Preço do boi gordo (R $\$ / \mathrm{kg})$ & 186 & 1.4 & 0.3 & 0.9 & 2.0 \\
Preço da cana-de-açúcar (R $\$ /$ ton) & 186 & 10.0 & 1.3 & 7.0 & 14.3 \\
Preço do bezerro (R $\$$ cabeça) & 186 & 126.7 & 30.9 & 65.9 & 215.5 \\
Folha de pagamento (ind 2006=100) & 186 & 59.4 & 8.3 & 47.3 & 88.7 \\
Taxa de câmbio real & 186 & 96.6 & 19.4 & 72.0 & 154.5 \\
\hline
\end{tabular}

As cotações da arroba do boi gordo, do preço da carne de traseiro no atacado, da quantidade de carne produzida e do preço do bezerro foram obtidas no site do IEA (Instituto de Economia Agrícola do Estado São Paulo). O preço da tonelada de cana-de-açúcar recebido pelo agricultor é coletado pela Secretaria da Agricultura e do Abastecimento do Estado do Paraná, Departamento de Economia Rural (Seab-PR), e extraído do Ipeadata.

O efetivo de bovinos e o número de bovinos abatidos foram obtidos no site do SIDRA (Sistema IBGE de Recuperação Automática), da Pesquisa Pecuária Municipal e da Pesquisa Trimestral do Abate de Animais, respectivamente. A série de efetivo de bovinos é anual - conhece-se somente o valor do estoque no último mês de cada ano. Essa variável representa o estoque de bovinos no mercado e, portanto, é uma medida do estado desse mercado, que influencia o custo de oportunidade do boi no pasto. Dada a relevância dessa variável, decidiu-se mensalizar a variável para utilizá-la nas estimativas. Para calcular o valor do estoque mensal de bois, utilizou-se da taxa bruta de crescimento do rebanho para cada ano que, subtraído o abate mensal, faz a série atingir o valor de dezembro do próximo ano. Utilizou-se a seguinte equação de movimento para estimar a série de efetivo de bovinos:

$$
E_{t}=r^{n} \cdot E_{t-1}-\text { abate }_{t-1}
$$

Onde $E_{t}$ é o efetivo de bovino no período $t, r^{N}$ é a taxa bruta de crescimento do estoque de bovinos no ano $n$, e abate $t_{t}$ é quantidade (cabeças) de bovinos abatidos no mês $t$. Conhecendo os valores de dezembro de cada ano e a série mensal de abates, é possível construir a estimativa mensal de efetivo de bovinos.

Para isso, precisa-se calcular a taxa de crescimento bruta do rebanho $r^{n}$. Faz-se isso calculando uma taxa mensal e igual para todos os meses de um determinado ano, que projete um crescimento (ou diminuição) líquido do rebanho, que torne o valor previsto de dezembro do ano seguinte igual ao valor observado nos dados. Por exemplo, dada uma taxa de crescimento do rebanho e usando os dados de efetivo de dezembro de 2004 e do abate naquele mês, utiliza-se a equação (12) para calcular o efetivo em janeiro de 2005. Com estimativa de janeiro de 2005, calcula-se a estimativa de fevereiro de 2005 e assim por diante, até dezembro de 2005. A taxa bruta mensal de crescimento do efetivo em $2005\left(r^{05}\right)$ é aquela que iguala o valor estimado em dezembro de 2005 ao valor encontrado nos dados. 
Dados da folha de pagamento da indústria, uma proxy para a renda, são oriundos da Pesquisa Mensal do Emprego e Renda do IBGE e dados da taxa de câmbio real foram obtidos a partir do IPEADATA. Além de os preços serem deflacionados, os pesos estão em quilograma; por exemplo, o preço do boi gordo que é dado em arroba foi transformado para preço por quilo e assim por diante, até que todas as variáveis estivessem na mesma unidade de medida. As quantidades de bovinos (efetivo e abatido) estão por unidade.

\section{Testes, Estimações e Resultados}

Uma correta estimação da equação de oferta (equação 6) requer a análise e o eventual tratamento de uma série de questões que surgem devido a características da base de dados e do problema analisado. As subseções a seguir tratam dos problemas de raiz unitária e de endogeneidade.

\section{Raiz unitária}

Por se tratar de séries temporais de dados, realizou-se o teste Dickey-Fuller Aumentado (ADF) para detectar a presença de raiz unitária. Os resultados da Tabela 4 mostram a presença de raiz unitária em todas as variáveis explicativas do modelo, mas não na variável dependente. Esse resultado indica que é correto estimar o modelo com as variáveis em nível, em vez de utilizar a primeira diferença, caso a variável dependente tivesse raiz unitária.

Tabela 4

Teste Dickey-Fuller Aumentado de Raiz Unitária - Variáveis em Nível

\begin{tabular}{lcc} 
& Estatística ADF & p-valor (MacKinnon) \\
\hline Número de abatidos & -3.22 & 0.02 \\
Preço boi gordo & -1.43 & 0.57 \\
Número Efetivo & -0.54 & 0.88 \\
Preço do bezerro & -0.18 & 0.94 \\
Preço da cana-de-açúcar & -1.81 & 0.38 \\
\hline
\end{tabular}

Para obter uma confirmação mais forte, o teste proposto por Engle e Granger (1987) foi utilizado para verificar se a combinação linear das variáveis em nível é estacionária. Para tanto, estimou-se o modelo dado pela equação (6) e aplicou-se o teste ADF ao resíduo da regressão. O resultado do teste, apresentado na Tabela 5, confirma que, mesmo que as séries individuais fossem integradas de ordem 1 , $I(1)$, as séries cointegram-se, ou seja, a combinação linear delas é integrada de ordem zero, $C I(0)$. Por essa razão, estimou-se o modelo com as variáveis em nível.

Tabela 5

Teste Dickey-Fuller Aumentado de Raiz Unitária -Resíduo

\begin{tabular}{lcc}
\cline { 2 - 3 } & Estatística ADF & P-valor (MacKinnon) \\
\hline Resíduo & -4.65 & 0.0001 \\
\hline
\end{tabular}




\section{Endogeneidade}

A estimação da equação de oferta é melhor entendida como parte da estimação de um sistema de oferta e demanda, no qual cada observação de preço e quantidade representa o equilíbrio do mercado em um momento do tempo. É incorreto afirmar que preço causa quantidade ou vice-versa, pois ambos são endogenamente determinados no equilíbrio de mercado. A simples observação de uma amostra de pares de preço e quantidade não é suficiente para se desvendar o traçado da curva de oferta ou de demanda.

Outra maneira de se entender o problema da endogeneidade em sistemas de oferta e demanda é verificar que choques que deslocam a curva de oferta (demanda) afetam preço e quantidade de equilíbrio. Logo, o preço é correlacionado com o resíduo e, portanto, endógeno. A estimação desse modelo por Mínimos Quadrados Ordinários (MQO) geraria estimadores viesados. Necessita-se, por conseguinte, de variáveis instrumentais.

Do exposto, pode-se inferir que a variável instrumental deve ser (a) correlacionada com o preço do boi gordo e (b) não correlacionada com choques de oferta de boi gordo. Variáveis que deslocam a curva de demanda, tal como a renda dos consumidores, satisfazem as condições necessárias para ser uma variável instrumental para a estimação da curva de oferta. Essa tem sido a solução tradicionalmente apontada pela literatura: usar variáveis exógenas da equação da demanda como instrumento para o preço da curva de oferta, ver Epple e McCallu (2006) e Angrist e Krueger (2001) para uma discussão mais geral sobre variáveis instrumentais no contexto de estimação de oferta e demanda).

Como parte da produção de carne bovina é exportada e parte é consumida no mercado interno, as variáveis instrumentais utilizadas foram a folha de pagamento da indústria no estado de São Paulo (demanda interna) e a taxa de câmbio (demanda externa). As estimações foram feitas via Mínimos Quadrados em 2 Estágios (2SLS), e os resultados, incluindo os do primeiro estágio, encontram-se na Tabela 6.

\section{Estimações e resultados}

A Tabela 6 apresenta o resultado das diferentes especificações da oferta de bovinos. Os modelos 1 e 2 foram estimados via Mínimo Quadrado de Dois Estágios (2SLS) e o modelo 3, via Mínimo Quadrados Ordinários (OLS). Por incluir todo o conjunto de controles, a estimação 1 é o modelo-base a partir do qual se realizou a análise dos resultados. Os demais são apresentados para justificar a especificação adotada.

Tabela 6

Resultados: Curva de Oferta de Bovinos

\begin{tabular}{lcccc} 
& \multicolumn{2}{c}{ Modelo 1 - 2SLS $^{\S}$} & Modelo 2 $^{\S}$ & Modelo 3 $^{\S}$ \\
\hline \multirow{3}{*}{ Preço boi gordo } & $2^{\circ}$ Estágio & $1^{\circ}$ Estágio & 2 SLS & OLS \\
& $107.2^{*}$ & & $344.5^{*}$ & -6.575 \\
Rebanho efetivo & $(1.80)$ & & $(1.79)$ & $(-0.61)$ \\
& -6.625 & $0.104^{* * *}$ & -9.325 & $5.781^{*}$ \\
Abatidos (t-1) & $(-0.97)$ & $(8.31)$ & $(-0.52)$ & $(2.01)$ \\
& $0.820^{* * *}$ & $-0.000894^{* *}$ & & $0.761^{* * *}$ \\
Preço do bezerro & $(13.28)$ & $(-3.46)$ & & $(15.06)$ \\
& -0.669 & $0.00669^{* * *}$ & $-2.18^{*}$ & 0.161 \\
& $(-1.47)$ & $(11.93)$ & $(-1.48)$ & $(1.78)$ \\
\hline
\end{tabular}


Tabela 6 (continuação)

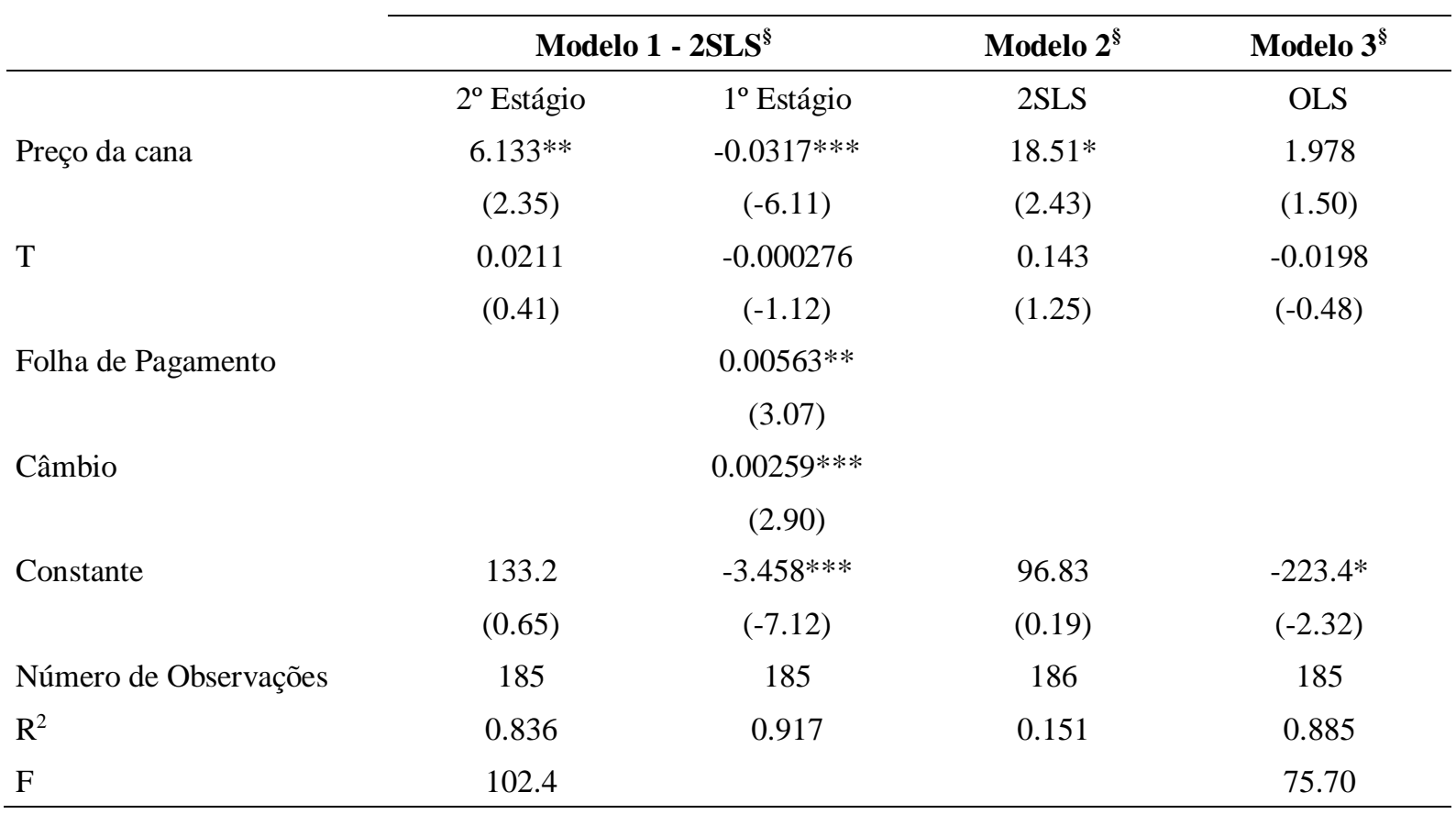

Nota. ${ }^{\S}$ Variável dependente é a quantidade mensal de bovinos abatidos; ${ }^{\times}$Estatísticas $t$ em parênteses; $\uparrow$ Todas as especificações contêm dummies de mês.

$* \mathrm{p}<0.05, * * \mathrm{p}<0.01, * * * \mathrm{p}<0.001$.

Como há interesse na elasticidade-preço da oferta, o coeficiente de interesse é o da variável preço boi gordo. Os coeficientes obtidos foram 107,2 e 344,5 nos modelos 1 e 2, respectivamente, significante a $5 \%$. A diferença se deve à ausência da variável dependente defasada entre os controles do modelo $3 \mathrm{e}$ mostra a magnitude do viés que se incorre com sua omissão.

O primeiro estágio é o mesmo para os modelos 1 e 2, e os resultados são mostrados em conjunto com o modelo 1. As duas variáveis instrumentais utilizadas, a taxa de câmbio e a folha de pagamento da indústria, mostraram-se fortemente significantes e com o sinal esperado. Isso demonstra que os instrumentos têm forte correlação com o preço do boi gordo.

O modelo 3 foi estimado via OLS e, portanto, não leva em conta a endogeneidade da variável de interesse, o preço do boi gordo. O coeficiente obtido para essa variável é significantemente menor do que os obtidos nos modelos estimados com variáveis instrumentais. Os modelos 1 e 2 são úteis para se observar o efeito da variável dependente defasada, Abatidos $(t-1)$, na autocorrelação dos resíduos. A estatística do teste Durbin-Watson tem valores 2,4 e 0,5 quando se inclui Abatidos $(t-1)$ ou não no modelo, respectivamente. Isso indica a presença de autocorrelação dos resíduos quando não se usa a variável dependente defasada como controle. Em todas as especificações, os desvios padrãos foram estimados com a especificação de sanduíche da variância, robusta a problemas de heteroscedasticidade.

Outras especificações foram estimadas via GMM para checar a robustez dos resultados. O GMM tem a vantagem de ser robusto a problemas nos resíduos, autocorrelação e heteroscedasticidade e usa variáveis instrumentais na estimação. Mas tem uma performance inferior ao 2SLS em amostras relativamente pequenas, como é o caso deste estudo. Por esse motivo, optou-se por apresentar e analisar somente os resultados estimados via 2 SLS. De qualquer forma, os resultados obtidos se mostraram muito semelhantes aos da Tabela 6 e encontram-se no Apêndice.

A inclusão de Abatidos(t-1) nos modelos estimados via 2SLS muda substancialmente o valor do coeficiente do preço do boi gordo. Excluí-la gera viés de variável omitida nos resultados, como evidenciado pela comparação entre os modelos 1 e 2 . 
O efetivo de bovinos não se mostrou estatisticamente significante. O preço da cana-de-açúcar é estatisticamente significante e apresentou o sinal esperado. Um aumento no preço da cana-de-açúcar induz uma substituição da criação de bovinos pelo plantio de cana. A consequência disso é um aumento do abate para reduzir o rebanho. O preço do bezerro representa o custo de reposição dos animais abatidos e, portanto, tem um efeito negativo no abate de bovinos, como obtido nas estimações.

Uma vez obtidos os parâmetros da oferta de bovinos, calculou-se a elasticidade da oferta, mês a mês. Na Tabela 7, elencam-se as estatísticas descritivas da elasticidade-preço da oferta. Esse é um resultado importante por si só, pois não se tem conhecimento de estimação da elasticidade da oferta de bovinos para o Brasil. O resultado obtido mostra uma elasticidade média próxima da unitária.

Tabela 7

Elasticidade Preço da Oferta de Bovinos

\begin{tabular}{lcccc}
\hline & Média & Desvio Padrão & Mínimo & Máximo \\
\hline Elasticidade & 0.95 & 0.24 & 0.60 & 1.92 \\
\hline
\end{tabular}

Tendo a série de elasticidades, estimou-se a condição de primeira ordem descrita pela equação (10). Os resultados de interesse são apresentados na Tabela 8. E possível perceber que os parâmetros estimados são positivos e estatisticamente significantes a $0,1 \%$. Os desvios padrões foram estimados via Bootstrap para corrigir o fato de que se está usando uma estimativa (elasticidade da oferta) como variável da regressão.

Tabela 8

\section{Resultados: Condição de Primeira Ordem§}

\begin{tabular}{cc}
\hline Preço do boi gordo $(\alpha 1)$ & $1.084 * * *$ \\
Preço do boi_elast $(\alpha 2)$ & $(15.20)$ \\
& $0.211 * * *$ \\
Número de Observações & $(5.07)$ \\
\hline $\mathrm{R}^{2}$ & 186 \\
\hline
\end{tabular}

Nota. ${ }^{\S}$ Variável dependente é a quantidade mensal de bovinos abatidos; ${ }^{\times}$Estatísticas $t$ em parênteses; Ф Desvios Padrão calculados via bootstrap; † Todas as especificações contêm os seguintes controles: dummies mensais, tendência temporal, tamanho do rebanho no país e os preços da cana, da soja e da carne suína.

$* \mathrm{p}<0.05, * * \mathrm{p}<0.01, * * * \mathrm{p}<0.001$.

O que de fato interessa é o uso desses coeficientes estimados para recuperar os parâmetros estruturais do modelo, que são a produtividade marginal $f_{B}$ e, principalmente, o poder de mercado $\theta$. Os valores dessas duas variáveis são apresentados na Tabela 9.

Tabela 9

Poder de Mercado e Produtividade Marginal

\begin{tabular}{cc}
\hline Poder de Mercado - theta $(\alpha 2 / \alpha 1)$ & 0.19 \\
Produtividade Marginal $-\mathrm{fB}(1 / \alpha 1)$ & 0.92 \\
\hline
\end{tabular}


Os resultados indicam um valor de theta igual a 0.19. Isso evidência dois pontos: (a) existência de poder de mercado e (b) em níveis moderados. Lembrando que o theta é um índice de poder de mercado que varia entre 0 e 1 .

Para a produtividade marginal do boi gordo, obtém-se $f_{B}=0.92$. Esse resultado corrobora empiricamente a crença inicial, baseada em relatos de pessoas da indústria, de que a produtividade marginal é estatisticamente igual a 1. A seguir, usa-se esse resultado para estimar o poder de mercado através do estimador dado pela equação (11). Os resultados encontram-se na Tabela 10.

Tabela 10

Poder de Mercado: Informação a priori

\begin{tabular}{|c|c|c|c|c|}
\hline & \\
\hline & Média & Desvio Padrão & Mínimo & Máximo \\
\hline Poder de mercado - theta' & 0.13 & 0.123 & -0.07 & 0.53 \\
\hline
\end{tabular}

A média dessa outra estimação, chamada de theta', é próxima da estimada usando a condição de primeira ordem -0.13 contra 0.19 na primeira, corroborando os resultados obtidos. Novamente, os resultados apontam para a existência de poder de mercado moderado/baixo.

Todos os resultados obtidos até agora se apoiam em hipóteses sobre a forma funcional da oferta de bovinos, o modelo de competição da indústria e a produtividade marginal do insumo. Como a todos os estudos sobre poder de mercado e conduta das firmas, os resultados obtidos dependem dessas hipóteses. A Figura 1 apresenta um resultado que é independente de todas essas hipóteses: a evolução da margem, ou do mark-up, da indústria - preço da carne menos preço do bovino.

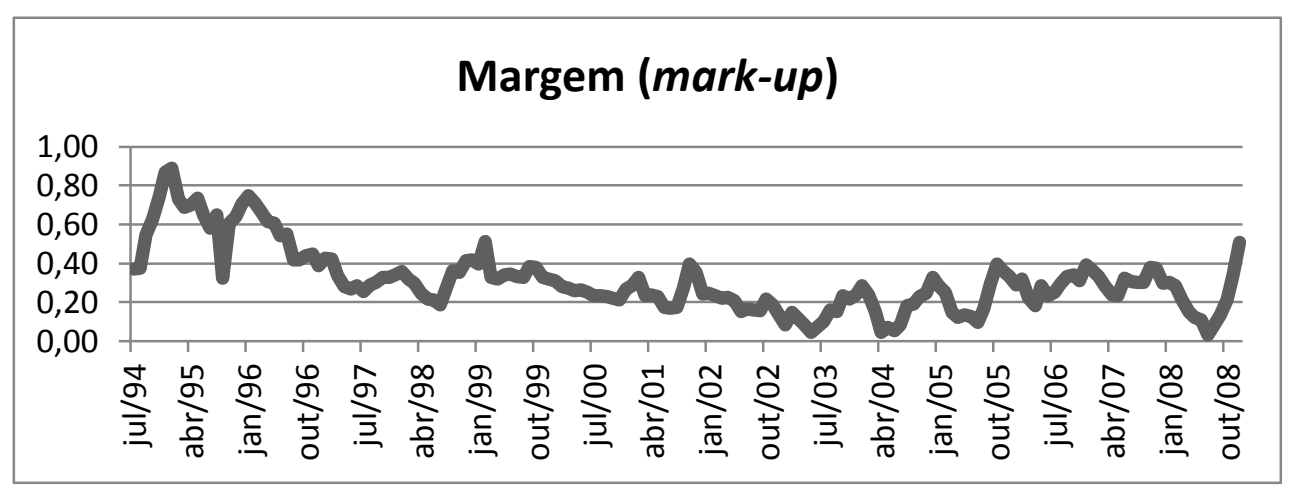

Figura 1. Evolução da Margem (Mark-up).

Pode-se verificar, através do gráfico, que os maiores mark-ups são observados por volta do ano de 1995. Os dados indicam uma queda constante da margem até o ano de 2004, quando volta a subir moderadamente até 2007, e oscila amplamente nos períodos finais da amostra. O que se pode afirmar é que não há uma tendência forte de aumento da margem na última década, que seria decorrente do aumento da concentração no setor.

\section{Conclusão}

Existe evidência (processo no CADE) e especulação de que a indústria frigorífica exerce poder de mercado sobre os produtores de gado de corte. Este trabalho procura se juntar ao restrito conjunto de artigos que tentam analisar esta relação de maneira científica. Para isso, analisa a evolução e a estrutura dos dois elos da cadeia de produção de carne bovina: produtores rurais e frigoríficos. 
A conclusão que se extrai é que os produtores rurais são muitos e distribuídos pelos principais estados produtores, enquanto os frigoríficos são grandes e poucos e concentram suas plantas nesses estados e em São Paulo, principal centro consumidor. Isso sustenta a hipótese de que a indústria tem a estrutura de um oligopsônio e que, portanto, tem potencial para exercer poder de mercado sobre os pecuaristas. A situação emblemática consiste no pecuarista de uma região relativamente isolada - São Paulo e partes do sudeste seriam a exceção, que depende de um único frigorífico para vender seu gado de corte. Essa dependência é o que gera a oportunidade de exercício de poder de mercado por parte do frigorífico.

A atuação de órgãos de defesa da concorrência deve levar em consideração a delimitação geográfica do mercado, aspecto fundamental na relação pecuarista-frigorífico.

$\mathrm{Na}$ análise empírica, o problema é abordado de duas maneiras. Primeiro, é usada uma estimativa da curva de oferta de bovinos e a condição de maximização de lucro dos frigoríficos para estimar o parâmetro de conduta desses últimos. Os resultados obtidos apresentam um parâmetro de conduta igual a 0.19 , evidenciando a existência de poder de mercado entre baixo e moderado. Além do parâmetro de conduta, esse método gera uma estimativa da produtividade marginal do boi gordo. Essa estimativa permite a utilização de outro método de estimação de poder de mercado.

Nesse método alternativo, utiliza-se a informação a priori (Urso, 2007, Yatabe, 2004, e evidências fornecidas por pessoas da indústria) - e corroborada pela primeira estimativa - de que a produtividade marginal de uma arroba de boi é igual a 1. Obtém-se resultado bastante similar, com o parâmetro de poder de mercado igual a 0.13 .

Ambos os resultados trazem evidência de que, no estado de São Paulo, o poder de mercado existe em grau fraco. Isso leva a descartar a hipótese de que o setor seja cartelizado ou que as maiores firmas se comportem como um monopsônio.

Além das estimativas, uma simples inspeção gráfica da margem média dos frigoríficos ao longo do tempo indica que esta não está subindo (ver Figura 1). Não é possível identificar um aumento do poder de mercado em anos recentes. O que indica que a onda de fusões e aquisições no setor frigorífico não teve reflexo na conduta das firmas.

Ao contrário, a margem média dos frigoríficos cai nos anos de 1990 e mantém-se estável ao longo da década passada. A queda da margem nos anos 1990 pode ter sido uma das responsáveis pela onda de consolidação do início do ano 2000. A consolidação seria uma estratégia de sobrevivência de firmas que teriam de aumentar suas margens via redução de custo ou aumento de poder de mercado. Essa é uma hipótese a ser confirmada em trabalhos futuros.

\section{Notas}

\footnotetext{
${ }^{1} \mathrm{O}$ maior rebanho do mundo é o indiano, com 282 milhões de reses, porém a pecuária deste país não se destina à comercialização. Portanto, para fins comerciais, o Brasil hoje possui o maior rebanho bovino do mundo. No que se refere à produção de carne, o Brasil está em segundo lugar no ranking, atrás dos Estados Unidos (Pita, 2013).

${ }^{2} \mathrm{O}$ subscrito $t$ é omitido para simplificar a expressão.
}

\section{Referências}

Andersen, T. B., Asche, F., \& Roll, K. H. (2008). Oligopoly and oligopsony power in concentrated supply chains [ISIAC Working Paper $\mathrm{n}^{\circ}$ 08-1]. Universidade de Stavanger, Ullandhaug, Stavanger, Noruega. 
Angrist, J., \& Krueger, A. B. (2001). Instrumental variables and the search for identification: from supply and demand to natural experiments. Journal of Economic Perspectives, 15(4), 69-85. doi: $10.3386 / \mathrm{w} 8456$

Appelbaum, E. (1982). The estimation of the degree of oligopoly power. Journal of Econometrics, 19(2/3), 287-299. doi: 10.1016/0304-4076(82)90006-9

Associação as Indústrias Brasileiras Exportadores de Carne. (2009). Mapas das plantas frigoríficas. Recuperado de http://www.abiec.com.br/2_mapa.asp\#

Bailey, D. von, Brorsen, B. W., \& Thomsen, M. R. (1995). Identifying buyer market areas and the impact of buyer concentration in feeder cattle markets using mapping and spatial statistics. American Journal of Agricultural Economics, 77(2), 309-318. doi: 10.2307/1243541

Baker, J. B., \& Bresnahan, T. F. (1988). Estimating the residual demand curve facing a single firm. International Journal of Industrial Organization, 6(3), 283-300. doi: 10.1016/S01677187(88)80012-2

Bresnahan, T. F. (1982). The oligopoly solution concept is identified. Economics Letters, 10(1/2), 8792. doi: 10.1016/0165-1765(82)90121-5

Bresnahan, T. F. (1989). Empirical studies of industries with market power, handbook of industrial organization. In R. Schmalensee \& R. Willig (Eds.), Handbook of industrial organization (Vol. 2, Chap 17, pp. 1011-1057). Amsterdan: Elsevier.

Cai, X., Stiegert, K., \& Koontz, S. (2011). Oligopsony fed cattle pricing: did mandatory price reporting increase meatpacker market power? Applied Economic Perspectives and Policy, 33(4), 606-622.

Caleman, S. M., \& Cunha, C. F. (2011). Estrutura e conduta da agroindústria exportadora de carne bovina no Brasil. Organizações Rurais \& Agroindustriais, 13(1), 93-108.

Conselho Administrativo de Defesa Econômica. (n.d.). JBS terá de informar compras de frigoríficos ao Cade pelos próximos 30 meses. Recuperado de http://www.cade.gov.br/Default.aspx?7db041c858cd22e1340153e072d4

Conselho Administrativo de Defesa Econômica. (2005). Ações judiciais contra os frigoríficos. Processo Administrativo $\mathrm{N}^{\circ}$ 08012.002493/2005-16.

Crespi, J. M., Gao, Z., \& Peterson, H. H. (2005). A simple test of oligopsony behavior with an application to rice milling. Journal of Agricultural \& Food Industrial Organization, 3(2), 1-17. doi: $10.2202 / 1542-0485.1117$

Crespi, J. M., Xia, T., \& Jones, R. (2010). Market power and the cattle cycle. American Journal of Agricultural Economics, 92(3), 685-697. doi: 10.1093/ajae/aap034

Durham, C. A., \& Sexton, R. J. (1992). Oligopsony potential in agriculture: residual supply estimation in California's processing tomato market. American Journal of Agricultural Economics, 74(4), 962-972. doi: 10.2307/1243194

Engle, R. F., \& Granger, C. W. J. (1987). Co-integration and error-correction: representation, estimation, and testing. Econometrica, 55(2), 251-276.

Epple, D., \& McCallun, B. (2006). Simultaneous equation econometrics: the missing example. Economic Inquiry, 44(2), 374-384. doi: 10.1093/ei/cbj022

Governo Federal dá prioridade a grandes frigoríficos. (2010, agosto, 9). Valor Econômico, Ano 3. 
Instituto Brasileiro de Geografia e Estatística. (1997). Censo agropecuário 1995-1996. Rio de Janeiro: Autor.

Instituto Brasileiro de Geografia e Estatística. (2006). Censo agropecuário 2006. Rio de Janeiro: Autor.

Instituto Brasileiro de Geografia e Estatística. (2008). No $1^{a}$ trimestre do ano, abate de bovinos registra primeira queda desde 97. Comunicação Social. Rio de Janeiro: Autor.

Instituto Brasileiro de Geografia e Estatística. (2009). Estatística da produção pecuária. Rio de Janeiro: Autor.

Ji, I. B., \& Chung, C. (2010). Dynamic assessment of oligopoly, oligopsony power, and cost efficiency using the new empirical industrial organization in the U.S. beef packing industry [Working Paper], Oklahoma State University, Stillwater, Oklahoma, EUA.

Koontz, S. R., Garcia, P., \& Hudson, A. (1993). Meatpacker conduct in fed cattle pricing: an investigation of oligopsony power. American Journal of Agricultural Economics, 75(3), 537-548.

Lau, L. J. (1982). On identifying the degree of competitiveness from industry price and output data. Economics Letters, 10(1/2), 93-99. doi: 10.1016/0165-1765(82)90122-7

Lopez, R. A., Azzam, A. M., \& Lirón-España, C. (2002). Market power and/or efficiency: a structural approach. Review of Industrial Organization, 20(2), 115-126. doi: 10.1023/A:1013867114881

Macedo, P. C. A. de, \& Lima, L. C. O. de (2011). Oligopólio mundial, investimento estratégico e arena competitiva: o caso da indústria frigorífica de carne bovina brasileira. Anais do Simpósio de Excelência em Gestão $e$ Tecnologia. Recuperado de http://www.aedb.br/seget/artigos11/63214832.pdf

Neves, M. F. (2000). Redes agroalimentares \& marketing da carne bovina em 2010. Anais do Congresso Brasileiro de Raças Zebuínas. Uberaba, MG, Brasil, 4.

Novilho Superprecoce. (2009, outubro). Revista Dinheiro Rural, Ano 06, Edição 60.

Paul, C. J. M. (2001). Cost economies and market power: the case of the U.S. meat packing industry. The Review of Economics and Statistics, 83(3), 531-540.

Perloff, J. M., Karp, L. S., \& Golan, A. (2007). Estimating market power and strategies. Cambridge, Reino Unido: Cambridge University Press.

Pita, A. (2013, outubro 10). Rebanho bovino brasileiro é o segundo maior do mundo. Estadão. Recuperado de http://economia.estadao.com.br/noticias/negocios,rebanho-bovino-brasileiro-e-osegundo-maior-do-mundo, $167062 \mathrm{e}$

Pitelli, M. M., \& Mendonça, E. C. (2008). Eficiências de escala, sinergia e concentração no setor frigorífico de carne bovina: uma aplicação utilizando-se a metodologia DEA. Anais do Congresso da SOBER. Piracicaba, SP, Brasil, 46.

Schmalensee, R. (1989). Inter-industry studies of structure and performance, handbook of industrial organization. In R. Schmalensee \& R. Willig (Eds.), Handbook of industrial organization (Vol. 2, Chap. 16, pp. 951-1009). Amsterdan, Holanda: Elsevier.

Schroeter, J. R. (1988). Estimating the degree of market power in the beef packing industry. The Review of Economics and Statistics, 70(1), 158-162.

Schroeter, J. R., \& Azzam, A. (2004). Captive supplies and cash market prices for fed cattle: the role of delivery timing incentives. Agribusiness, 20(3), 347-362. doi: 10.1002/agr.20011 
Schroeter, J. R., Azzam, A. M., \& Zhang, M. (2000). Measuring market power in bilateral oligopoly: the wholesale market for beef. Southern Economic Journal, 66(3), 526-547.

Stiegert, K. W., Azzam, A., \& Brorsen, B. W. (1993). Markdown pricing and cattle supply in the beef packing industry. American Journal of Agricultural Economics, 75(3), 549-558. doi: $10.2307 / 1243562$

Urso, F. S. P. (2007). A cadeia de carne bovina no Brasil: uma análise de poder de mercado e teoria da informação (Tese de doutorado). Fundação Getúlio Vargas, São Paulo, SP, Brasil.

Ward, C. E., Koontz, S. R., \& Schroeder, T. C. (1998). Impacts from captive supplies on fed cattle transaction prices. Journal of Agricultural and Resource Economics, 23(2), 494-514.

Yardley-Podolsky, W. J. H. (1981). Um perfil das indústrias de carnes e de seu futuro. Revista de Administração de Empresas, 21(2), 49-58. doi: 10.1590/S0034-75901981000200005

Yatabe, S. S. (2004). Utilização do contrato futuro do boi gordo da BM\&F para operação de "Hedge" de custo de matéria prima (Tese de mestrado). Pontifícia Universidade Católica de São Paulo, São Paulo, SP, Brasil.

Zhang, M., \& Sexton, R. J. (2000). Captive supplies and the cash market price: a spatial markets approach. Journal of Agricultural and Resource Economics, 25(1), 88-108.

Zheng, X., \& Vukina, T. (2009). Do alternative marketing arrangements increase pork packers' market power? American Journal of Agricultural Economics, 91(1), 250-263. doi:10.1111/j.14678276.2008.01185.x 


\section{APÊNDICE}

\section{Estimação Via GMM. Teste de Robustez}

\begin{tabular}{lccc}
\hline & Modelo 4 & Modelo 5 & Modelo 6 \\
\cline { 2 - 4 } Preço boi gordo & $124.0^{*}$ & 210.9 & $19.17^{*}$ \\
& -1.97 & -1.8 & -2.15 \\
Rebanho Efetivo & -8.948 & -10.77 & \\
& $(-1.28)$ & $(-1.28)$ & $0.855^{* * *}$ \\
Abatidos (t-1) & $0.834^{* * *}$ & $0.953^{* * *}$ & -23.12 \\
& -13.15 & -7.15 & \\
Preço do bezerro & -0.816 & -1.23 & \\
& $(-1.69)$ & $(-1.71)$ & \\
Preço da cana & $6.716^{*}$ & $7.141^{*}$ & 0.0102 \\
& -2.47 & -2.34 & -0.25 \\
T & 0.039 & -0.0185 & \\
Soja & -0.77 & $(-0.27)$ & \\
Suína & & -122.1 & \\
C & & $(-1.17)$ & -20.12 \\
& & -31.96 & $(-1.74)$ \\
\hline
\end{tabular}

Nota. ${ }^{\S}$ Variável dependente é a quantidade mensal de bovinos abatidos; ${ }^{\times}$Estatísticas $t$ em parênteses; $\uparrow$ Todas as especificações contêm dummies de mês.

$* \mathrm{p}<0.05, * * \mathrm{p}<0.01, * * * \mathrm{p}<0.001$. 